\title{
The Use and Abuse of Human Growth Hormone in Sports
}

\author{
David M. Siebert, MD, ${ }^{* \dagger}$ and Ashwin L. Rao, $\mathrm{MD}^{\dagger}$
}

Context: Recombinant human growth hormone ( $\mathrm{rHGH}$ ) has become a target of abuse in the sporting world. Conversely, sports medicine clinicians may encounter athletes using rHGH to achieve normalcy in the context of growth hormone (GH) deficiency.

Evidence Acquisition: Medline and PubMed databases were queried using the following keywords: GH, GH physiology, GH deficiency, acromegaly, GH athlete, GH sports, GH athletic performance, and GH deficiency concussion. Articles focusing on GH physiology, deficiency, excess, and its effects in both deficient and healthy patients were included.

\section{Study Design: Clinical review.}

\section{Level of Evidence: Level 3.}

Results: GH is a naturally occurring hormone with important roles in human physiology. Patients with GH deficiency (GHD) present variably, and GHD has numerous etiologies. rHGH treatment has substantial therapeutic benefits for patients with GHD. The benefits of rHGH treatment in otherwise-healthy adults are uncertain. GH excess may cause health problems such as acromegaly. Professional, collegiate, and international sports leagues and associations have banned rHGH use to maintain athlete health, safety, and fair play. Athletes misusing GH may face prolonged suspensions from competition. Implementing GH abuse testing is challenging, but new methods, such as the biomarker testing procedure, are being finalized.

Conclusion: rHGH is not only an important therapeutic agent for GH-deficient patients but also a target of abuse in competitive athletics. Its benefits in a healthy, adult population are uncertain. A safe exercise and competition plan, developed with a physician knowledgeable of GH use, physiology, and abuse potential, should be of benefit to a longitudinal clinician-patient relationship.

Keywords: human growth hormone; athlete; performance-enhancing drugs; athletic performance; drug testing

G rowth hormone $(\mathrm{GH})$, also known as somatotropin, is a 191-amino acid protein that plays a crucial role in human physiology. First isolated from humans in the 1950s, GH drives numerous physiologic processes, including skeletal and organ growth, calcium homeostasis, lipolysis, and the regulation of lean body mass. ${ }^{24}$ While exogenous $\mathrm{GH}$ replacement is effective in treating deficient patients, its theorized effects on the muscular and other systems have made it a target of abuse in the sporting world. Facing growing $\mathrm{GH}$ use and abuse by athletes, professional leagues, the National Collegiate Athletic Association (NCAA), and the International Olympic Committee (IOC) have prohibited its use. The IOC was one of the first to do so in 1989, with Major League Baseball the most recent to follow suit in 2005. Implementing GH testing has been subject to a number of obstacles, such as league collective bargaining agreements. The compound's low urinary excretion also prevented earlier testing protocols from reliably detecting abuse. $^{56}$ Nevertheless, all major American sports leagues now list GH on banned substance lists, ${ }^{35,41,43,45,46}$ as does the World Anti-Doping Agency (WADA). ${ }^{72}$

Concerns over GH abuse in sports include athlete safety, the association of other performance-enhancing drugs (PEDs), and the preservation of fair play and competition. The sports medicine clinician must be aware of the most recent evidence, policies, and ethical issues surrounding $\mathrm{GH}$ when an at-risk athlete or GH-deficient patient is identified.

From ${ }^{\dagger}$ Department of Family Medicine, Sports Medicine Section, University of Washington, Seattle, Washington

*Address correspondence to David M. Siebert, MD, Department of Family Medicine, Sports Medicine Section, University of Washington, 3800 Montlake Boulevard, Seattle, WA 98195 (email: siebert@uw.edu) (Twitter: @DaveMSiebert).

The following author declared potential conflicts of interest: Ashwin L. Rao, MD, has received payment for serving as an AMSSM MSK ultrasound course teacher.

DOl: $10.1177 / 1941738118782688$

(C) 2018 The Author(s) 


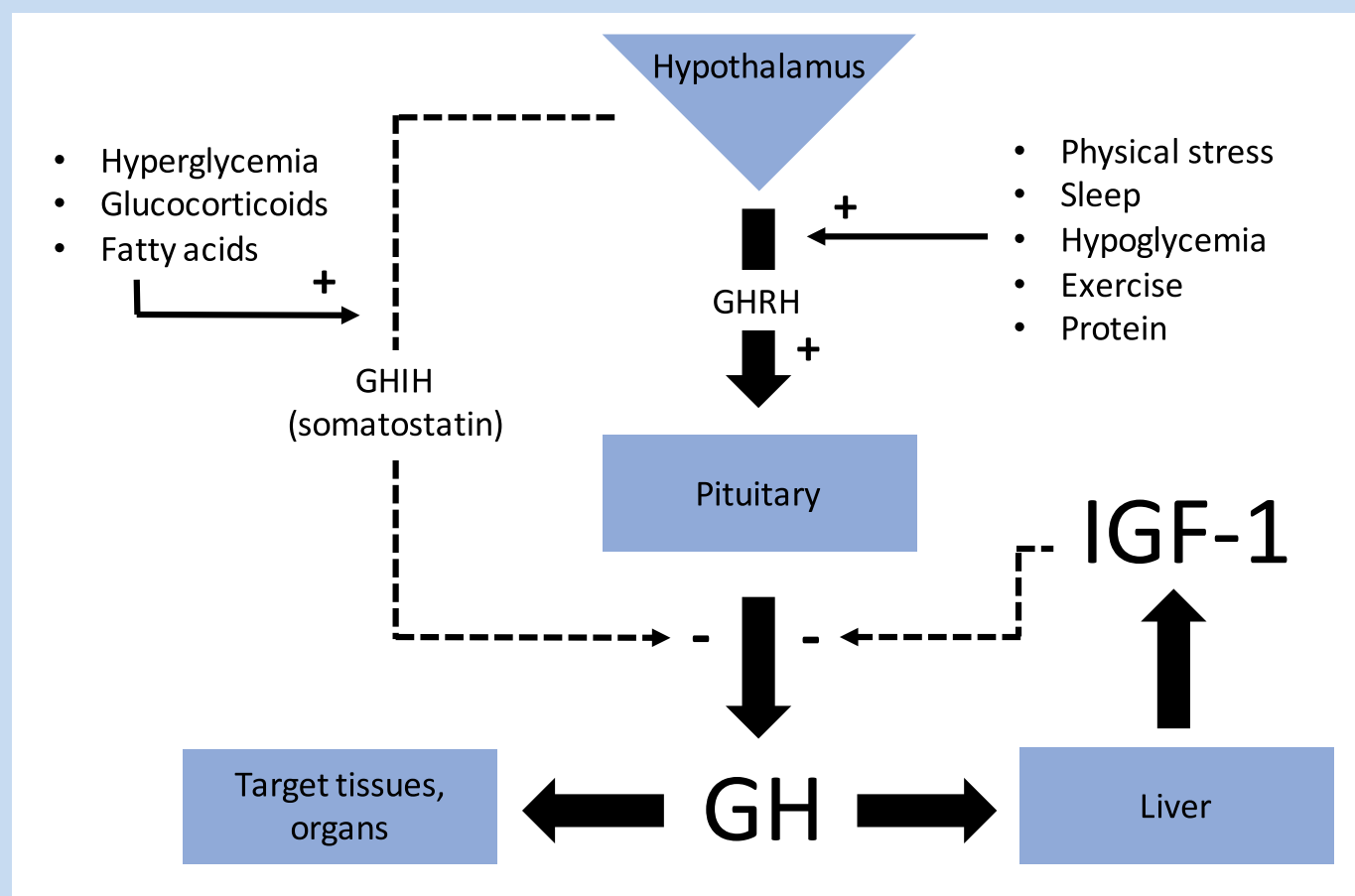

Figure 1. GH, IGF-1 axis. GH, growth hormone; GHRH, growth hormone-releasing hormone; GHIH, growth hormone-inhibiting hormone; IGF-1, insulin-like growth factor-1.

\section{NORMAL PHYSIOLOGY OF GROWTH HORMONE}

$\mathrm{GH}$ is produced by the anterior pituitary gland. The primary function of GH is to increase height via the proliferation of chondrocytes, though it has a number of functions in normal homeostasis and growth and development. ${ }^{10,24} \mathrm{GH}$ imparts its actions by stimulating the hepatic production of insulin-like growth factor 1 (IGF-1), which in turn promotes the growth of body organs and bones. ${ }^{10,24}$ Total daily GH production is highest in childhood and adolescence and declines with age. ${ }^{10,24}$ Secondary functions of GH include regulating lipolysis, enhancing glucose availability, maintaining calcium homeostasis and bone health, increasing lean body mass, and helping regulate immune system function via a number of proposed pathways. $^{10,24,36}$

A balance of stimulators and inhibitors of $\mathrm{GH}$ release regulates its secretion from pituitary somatotroph cells. Two hypothalamic hormones, growth hormone-releasing hormone (somatoliberin) and growth hormone-inhibiting hormone (somatostatin), stimulate and inhibit GH secretion, respectively. ${ }^{10,24}$ Other GH secretion stimulants include sleep, stress, exercise, protein ingestion, and hypoglycemia, while GH secretion inhibitors include IGF-1, hyperglycemia, free fatty acids, and glucocorticoids. ${ }^{10,24}$ The resulting balance of stimulators and inhibitors (Figure 1) yields a pulsatile cycle of GH release from the pituitary gland. ${ }^{10,24}$ The largest daily surge of GH secretion occurs shortly after the onset of sleep, and smaller pulses occur at intervals throughout the day. ${ }^{10,24}$

\section{DIAGNOSIS AND TREATMENT OF GH DEFICIENCY}

\section{Childhood}

GH deficiency (GHD) affects approximately 1 in 3500 children ${ }^{33}$ The congenital form of the disease often presents in early childhood as growth failure. Severe cases can cause neonatal hypoglycemia and hyperbilirubinemia. Acquired GHD may follow central nervous system disease, infection, or head trauma. ${ }^{13}$ While the hallmark of GHD is growth failure or decreased growth velocity, no single test can definitively diagnose GHD. GHD can also vary in level of severity, from partial deficiency to complete. ${ }^{23}$ The Growth Hormone Research Society recommends "(integrating) all available data (clinical, auxological [growth and development], radiological, and biochemical) when making a diagnosis." ${ }^{23}$ This could include clinical history, plotting growth over time, identifying pituitary pathology or delayed bone age, or abnormal laboratory testing. Laboratory diagnosis may include a low peak serum GH concentration or a blunted response to $\mathrm{GH}$ secretion provocation with insulin, clonidine, glucagon, or amino acids. Various GH secretion provocation protocols have been described, ${ }^{51}$ each with their own potential side effects. For example, a $0.5-\mathrm{g} / \mathrm{kg}$ intravenous infusion of arginine will cause 
Table 1. Diagnostic criteria for pediatric $\mathrm{GHD}^{23}$

\begin{tabular}{|c|c|}
\hline Data Type & Possible Findings \\
\hline Clinical and historical & $\begin{array}{l}\text { - } \text { Neonatal hypoglycemia } \\
\text { - } \text { Prolonged hyperbilirubinemia or jaundice } \\
\text { - } \text { Microphallus } \\
\text { - } \text { Traumatic delivery } \\
\text { - } \text { Signs of an intracranial lesion } \\
\text { - } \text { History of cranial irradiation } \\
\text { - } \text { History of head trauma } \\
\text { - } \quad \text { Craniofyciacial midline abnormalities } \\
\text { - } \text { Other signs of pituitary dysfunction }\end{array}$ \\
\hline Auxological & $\begin{array}{ll}\text { - Growth failure } \\
\circ \text { Height more than } 3 \mathrm{SDs} \text { below the mean for age } \\
\circ \text { Predicted height }{ }^{a} \text { more than } 1.5 \mathrm{SDs}^{b} \text { below midparental height } \\
& \text { Slow or slowing growth velocity }\end{array}$ \\
\hline Radiographic & $\begin{array}{l}\text { - Decreased bone age on plain radiographs } \\
\text { - Pituitary or midline abnormalities on MRI }\end{array}$ \\
\hline Biochemical & $\begin{array}{l}\text { - Low }(<10 \mu \mathrm{g} / \mathrm{L}) \text { serum } \mathrm{GH} \text { concentration after provocation testing } \\
\text { - Abnormal genetic testing }\end{array}$ \\
\hline
\end{tabular}

GH, growth hormone; GHD, growth hormone deficiency; MRI, magnetic resonance imaging.

${ }^{a}$ Calculating predicted height: Extrapolate current height percentile to 19 years of age. ${ }^{58}$

${ }^{b} 1 \mathrm{SD}=4.25 \mathrm{~cm} ; 1.5 \mathrm{SD}=6.375 \mathrm{~cm} ; 2 \mathrm{SD}=8.5 \mathrm{~cm} .{ }^{58}$

${ }^{c}$ Calculating midparental height: (Average of mother's and father's height) $-13 \mathrm{~cm}$ (for girls) or $+13 \mathrm{~cm}$ (for boys). ${ }^{58}$

a peak serum GH concentration between 30 and 60 minutes after administration. A peak provoked $\mathrm{GH}$ concentration of $<10 \mu \mathrm{g} / \mathrm{L}$ supports the diagnosis of GHD (Table 1). ${ }^{57}$

Historically, human GH (HGH) extracted from cadavers was used to treat GHD. When the prion disease Creutzfeldt-Jakob was linked to extracted $\mathrm{HGH},{ }^{49}$ the Food and Drug Administration approved recombinant human $\mathrm{GH}(\mathrm{rHGH})$ in 1985 for the treatment of GHD. Since then, the list of approved indications for $\mathrm{rHGH}$ treatment has grown to include chronic renal insufficiency (1993), AIDS wasting syndrome (1996), Turner syndrome (1997), Prader-Willi syndrome (2000), small for gestational age (2001), idiopathic short stature (2003), short stature homeobox-containing gene deficiency (2006), and Noonan syndrome (2007). 2,28

Treatment of GH-deficient children should be initiated as soon as possible after diagnosis and ideally should include consultation with a pediatric endocrinologist. A typical dosing regimen is 25 to $50 \mu \mathrm{g} / \mathrm{kg} / \mathrm{d}$ injected subcutaneously. ${ }^{23}$ Normalization of the growth curve is the most important parameter to follow during treatment. Serum IGF-1 and IGF-binding protein-3 levels may also be followed. ${ }^{23}$

\section{Adulthood}

The Growth Hormone Research Society does not recognize "idiopathic isolated GHD occurring de novo in the adult (as a) diagnostic entity," ${ }^{25}$ while the Endocrine Society acknowledges it as "very rare." More commonly, adults may acquire GHD after traumatic brain injury, cranial irradiation, pituitary disease such as Sheehan syndrome, or other routes. ${ }^{25,39}$ Additionally, childhood GHD often persists into adulthood, even after maximal skeletal height is achieved. ${ }^{25,39}$ Evaluation for a diagnosis of new GHD in adulthood should be restricted to those with suspected pituitary dysfunction or past cranial irradiation or trauma. ${ }^{25,39}$ Serum IGF-1 levels can be used to screen for GHD when it is suspected, while GH secretion provocation tests are used to help confirm the diagnosis. ${ }^{25}$

Expert consult should be obtained before initiating treatment for adult GHD. A typical starting dose of $\mathrm{rHGH}$ is 0.2 to 0.3 $\mathrm{mg} / \mathrm{d}$ in younger adults and $0.1 \mathrm{mg} / \mathrm{d}$ in older adults. ${ }^{25}$ Precise age cutoffs for these regimens are not defined, and weightbased dosing is not advised because of variable $\mathrm{rHGH}$ absorption. The Endocrine Society recommends starting at a low dose and titrating according to clinical response, side effects, and serum IGF-1 levels. ${ }^{39}$ Adult doses are lower than pediatric doses, reflecting the normal age-related decline in endogenous GH production. During treatment, bone density should be measured through biennial dual energy x-ray absorptiometry scans to track increases in bone density. If increases are not observed, clinicians should review the $\mathrm{rHGH}$ dose and consider further investigations into other possible etiologies of low bone 
density. Body composition may also be tracked to evaluate for changes in lean body mass. Cardiovascular parameters, such as blood pressure, fasting glucose, and serum lipid concentrations, should also be monitored during treatment. Finally, and perhaps most important, quality of life should be tracked as a patientcentered outcome of treatment. ${ }^{25,39}$

In the case of a competitive athlete receiving appropriate treatment with $\mathrm{rHGH}$, an application for a therapeutic use exemption (TUE) from a league's HGH drug policy should be completed. Criteria and evidence to support the decision to approve an HGH TUE has been proposed by the WADA. ${ }^{71}$ Further information about obtaining a TUE is accessible online via the WADA, ${ }^{73}$ United States Anti-Doping Agency (USADA), ${ }^{62}$ NCAA $^{42,44}$ or other league and association websites and communications.

\section{CONSEQUENCES OF EXCESS GH}

There are a number of health risks of excess GH such as acromegaly, a syndrome characterized by bony overgrowth. In the vast majority of cases, acromegaly results from a GH-secreting pituitary adenoma. ${ }^{64}$ Initial signs may include symptoms of local mass effect from the intracranial adenoma such as vision changes or headache, abnormal bone growth in the face, macroglossia, or sleep apnea due to airway soft tissue hypertrophy. ${ }^{64}$ Water retention and resulting tissue edema may lead to nerve compression syndromes such as carpal tunnel syndrome. Impaired fasting glucose, outright diabetes mellitus, and various lipid disorders may develop. ${ }^{64}$ Hypertension, cardiomyopathies, valve disorders, and arrhythmias are also common. ${ }^{64}$

Patients receiving a diagnosis of acromegaly should be evaluated for associated comorbidities, including the above cardiovascular and metabolic diseases, other hormone derangements seen in hypopituitarism, and neuropsychiatric changes. ${ }^{30}$ While there is controversy regarding a higher malignancy risk in the setting of acromegaly, the disease appears to increase the risk of colon $^{54}$ and thyroid ${ }^{67}$ cancers. Recent guidelines recommend performing a screening colonoscopy at the time of acromegaly diagnosis and thyroid ultrasound if palpable nodularity exists. ${ }^{30}$

Acromegaly treatment is aimed at the normalization of $\mathrm{GH}$ and IGF-1 concentrations. In patients who are appropriate surgical candidates, transsphenoidal resection of the GH-secreting adenoma is the treatment of choice. ${ }^{30}$ Medical therapy with somatostatin receptor ligands such as octreotide is also an option, especially in poor surgical candidates or those with residual disease despite resection. GH receptor antagonists such as pegvisomant can be used in conjunction with somatostatin receptor ligands. Radiotherapy may also be beneficial in some cases. ${ }^{30}$

\section{EFFECTS OF GH ON BODY COMPOSITION AND ATHLETIC PERFORMANCE}

In 1981, bodybuilder Daniel Duchaine published The

Underground Steroid Handbook, bringing attention to HGH use as a way to improve athletic performance. Indeed, the use of rHGH to replace endogenous GH in deficient patients shows considerable and reproducible benefits. In contrast, in the decades after Duchaine's work, research on the advantages conferred by exogenous $\mathrm{GH}$ use in healthy patients has yielded mostly inconclusive or negative results. ${ }^{34,37}$

In the patient with GHD, multiple studies have demonstrated that treatment with exogenous $\mathrm{GH}$ increases lean body mass and decreases total body fat. ${ }^{8,20,22,53,74}$ With ongoing treatment, "a near normalization" of these measurements after 3 years of continuous therapy can be attained. ${ }^{29}$ Bone mineral density also increases with GH replacement, ${ }^{4,22,74}$ though a decrease in bone mineral density may first be observed before an overall increase is achieved. ${ }^{11}$

Aerobic exercise capacity also improves with $\mathrm{GH}$ replacement in deficient adults. ${ }^{6,12,15,29,40,66}$ A double-blind, placebo-controlled trial of GHD patients showed improvement in maximal oxygen uptake $\left(\mathrm{VO}_{2 \max }\right)$, ventilatory threshold, and maximal power output when treated with rHGH compared with placebo. ${ }^{15}$ Similar findings of improved $\mathrm{VO}_{2 \max }{ }^{6,12,40}$ power output, ${ }^{29,40}$ and functional capacity in metabolic equivalents ${ }^{12}$ were reported in later studies. A meta-analysis of 11 randomized, double-blind, placebo-controlled studies concluded "there is strong evidence that GH replacement improves exercise performance in GH-deficient patients." ${ }^{166}$ Furthermore, impaired exercise capacity in patients with GHD may predict functional response to treatment with $\mathrm{HHGH}^{68}$

Patients with GHD exhibit decreased muscle mass with a resulting reduction in strength. ${ }^{11,16,55}$ The effects of $\mathrm{GH}$ replacement on muscle function are not as clear as its influence on exercise capacity. GH replacement appears to increase muscle mass in the short term. However, while a positive effect on strength was seen in 1 study after 6 months of treatment, ${ }^{55}$ an effect on only limb girdle muscles was seen in another. ${ }^{14} \mathrm{~A}$ meta-analysis concluded that "although long-term open-label studies provide compelling evidence that $\mathrm{GH}$ replacement in GHD improves muscle strength over a period of 1 to 10 years, the current meta-analysis of placebo-controlled trials fails to confirm this," going on to suggest that "the short-term nature" of the studies involved as well as design differences may be to blame for the analysis' primary conclusion. ${ }^{65}$

The benefits of $\mathrm{GH}$ replacement in deficient patients do not clearly extend to healthy adults. A recent meta-analysis reviewed 44 randomized trials comparing $\mathrm{GH}$ treatment with no treatment to evaluate the effects of $\mathrm{GH}$ administration to healthy adults. ${ }^{34}$ While GH increased lean body mass, strength was not increased. Exercise capacity may actually worsen, and adverse events, such as edema and fatigue, were more common with the use of exogenous $\mathrm{GH}^{34}$

A 2010 study funded by the WADA came to similar conclusions. In this randomized, placebo-controlled, blinded study of healthy recreational athletes receiving $\mathrm{GH}$, GH with concurrent testosterone, or placebo, athletes receiving $\mathrm{GH}$ demonstrated increased lean body mass and decreased fat mass. GH treatment also yielded higher sprint capacity. However, 
other parameters of athletic performance, including $\mathrm{VO}_{2 \max }$, strength, and power, did not change. ${ }^{37}$

Both studies make a critical point in that $\mathrm{GH}$ dosing in research settings may not reflect the potentially higher doses or more intensive regimens used in the PED subculture. ${ }^{34,37}$ For instance, one review suggested an average daily dose of 4 IU (international units) in abuse regimens. ${ }^{56}$ With a conversion rate of $3 \mathrm{IU} / \mathrm{mg}$, an average HGH abuser may use as much as 6.67 times more hormone as a young adult, who receives a starting dose of $0.2 \mathrm{mg} / \mathrm{d} .{ }^{25}$ It is unknown whether side effects of $\mathrm{GH}$ abuse, including cardiovascular pathology, carpal tunnel syndrome, neuropsychiatric complaints, and other symptoms seen in acromegaly, are more likely to manifest in these high-dose regimens. As such, there exists an ethical quandary of designing a research study to analyze the effects of $\mathrm{GH}$ abuse regimens.

Despite some seemingly conclusive benefits of GH replacement in deficient patients, GH supplementation to enhance physical performance in normal, healthy adults is a separate clinical question with unclear answers. Whereas the goal of GH replacement in deficiency is to achieve normal physiology, the presumed goal of GH abuse is to reach supraphysiologic levels to confer a competitive advantage. Those advantages are, to date, largely unproven. Potential adverse effects must be considered given the widespread, multisystem effects of $\mathrm{GH}$ excess in acromegaly. Health risks may be amplified if GH is abused in cycles with other PEDs in an attempt to gain a theorized synergistic effect. Concomitant anabolic steroid abuse rates may be as high as $100 \%$ in select populations. ${ }^{7}$

\section{GHD, CONCUSSION, AND REPETITIVE HEAD TRAUMA}

Of potential interest to the sports medicine clinician is the question of a link between concussion or chronic, repetitive head impacts and GHD. Limited, thought-provoking data are available. In 2004, significantly lower levels of serum GH and IGF-1 were reported in active or retired boxers after provocation testing when compared with age-, body mass index-, and sex-matched controls. ${ }^{31}$ The same research group noted similar results in kickboxers ${ }^{59}$ and again later in boxers. ${ }^{61}$ These studies led to the recommendations of routine investigation of pituitary function in all retired contact sport athletes, and to consider screening active athletes with a history of concussion or signs of pituitary dysfunction. ${ }^{60}$ Similar conclusions have also been made. ${ }^{18}$

One case report of a GHD diagnosis after concussion has also been published. ${ }^{27}$ A previously healthy 14 -year-old male athlete developed hypopituitarism, including GHD, after 4 separate head injuries over a 4-month period. The fourth injury was diagnosed as a concussion; he did not report the first 3 to medical personnel. A second case report details the diagnosis of severe GHD 27 months after a concussion in an 18-year-old female ringette and basketball player with a history of multiple prior concussions, highlighting "the importance of maintaining a high index of suspicion for neuroendocrine abnormalities in athletes with persistent symptoms after sport concussion."32

While the potential connection between concussion or repetitive head trauma and GHD is compelling, current studies should be interpreted with caution until more rigorous investigations are completed.

\section{GH ABUSE AND TESTING IN SPORTS}

Despite unconvincing evidence of conferring performance enhancement, HGH abuse is a known problem within the sporting world, even at the pediatric level. ${ }^{9}$ As many as $5 \%$ of high school athletes ${ }^{52}$ and $24 \%$ of community gym members ${ }^{3}$ report abusing $\mathrm{HGH}$, while $12 \%$ of male weightlifters ${ }^{7}$ abuse HGH or IGF-1. In 2007, the results of an exhaustive investigation into PED use in Major League Baseball showed numerous professional baseball players linked to $\mathrm{HGH}^{38}$

Detecting exogenous HGH abuse is challenging, often leading to criticism of $\mathrm{HGH}$ testing protocols in sports leagues. ${ }^{50} \mathrm{GH}$ 's short half-life of approximately 4 hours after subcutaneous injection and 22 minutes after intravenous injection, pulsatile secretion pattern dependent on numerous variables, and low urinary excretion make detection of supraphysiologic concentrations in blood or urine samples difficult. Most testing protocols use the "isoform" blood testing strategy, which takes advantage of the fact that exogenous rHGH is synthesized as the $22-\mathrm{kDa}$ isoform. While structurally identical to $22-\mathrm{kDa}$ endogenous $\mathrm{GH}$, the administration of exogenous $22-\mathrm{kDa} \mathrm{GH}$ suppresses the pituitary secretion of other isoforms. Therefore, the ratio of the $22-\mathrm{kDa}$ isoform to other size isoforms will increase, signaling a positive test. ${ }^{5,26}$ Ideally, the test must be administered within 12 to 24 hours of the last rHGH dose to give the greatest chance of detection. ${ }^{5}$

A second testing strategy is currently being optimized, known as the "biomarker" strategy. This blood test indirectly assesses for supraphysiologic HGH concentrations by measuring the concentrations of its downstream products, IGF-1, and procollagen type III amino-terminal propeptide (P-III-NP), a byproduct of collagen III synthesis. By testing for IGF-1 and P-III-NP, which carry longer serum half-lives, the potential testing window is lengthened to as many as 7 days. ${ }^{5,26}$ The WADA used the biomarker strategy for a brief period during the 2012 Olympic Games. Biomarker testing was later stopped because of "the temporary withdrawal from the market [of] one of its constituent assays., ${ }^{70}$ The WADA, in conjunction with the USADA and other research groups, continues to research the validation of new IGF-1 and P-III-NP assays. Guidelines on the standardization of pretest sample handling, testing procedures, and the interpretation of results were published by the WADA in $2015 .{ }^{69}$ As of early 2018 , a study on the determination of assay decision limits is ongoing, with biomarker testing to resume at WADA-accredited laboratories upon its completion. ${ }^{70}$ Major League Baseball instituted HGH testing starting with the 2013 season, the National Football League with the 2014 season, and the National Basketball Association with the 2015-2016 
Table 2. Punishments for positive growth hormone tests by league

\begin{tabular}{|l|l|l|l|}
\hline League & \multicolumn{1}{|c|}{$\begin{array}{c}\text { Punishment (First } \\
\text { Positive Test) }\end{array}$} & \multicolumn{1}{|c|}{ Second Positive Test } & \multicolumn{1}{|c|}{ Third Positive Test } \\
\hline $\mathrm{NFL}^{45}$ & 4-game suspension & 8-game suspension & 2 season suspension; must apply for reinstatement \\
\hline $\mathrm{MLB}^{35}$ & 80-game suspension & 162-game suspension & Lifetime ban; may apply for reinstatement after 2 years \\
\hline $\mathrm{NBA}^{41}$ & 20-game suspension & 45-game suspension & Lifetime ban; may apply for reinstatement after 2 years \\
\hline $\mathrm{NHL}^{46}$ & 20-game suspension & 60-game suspension & Lifetime ban; may apply for reinstatement after 2 years \\
\hline $\mathrm{NCAA}^{43}$ & $\begin{array}{c}\text { 1 year suspension, } 1 \\
\text { year loss of eligibility }\end{array}$ & $\begin{array}{c}\text { Lifetime suspension, loss } \\
\text { of remaining eligibility }\end{array}$ & \\
\hline
\end{tabular}

MLB, Major League Baseball; NBA, National Basketball Association; NCAA, National Collegiate Athletic Association; NFL, National Football League; NHL, National Hockey League.

season. Positive tests generally result in progressively lengthening bans (and potentially lifetime disqualification) from competition for the guilty player (Table 2). The stigma of being caught may also have long-lasting consequences on the public's perception of an athlete.

\section{OFF-LABEL USE, LEGAL ISSUES, AND COUNSELING AT-RISK PATIENTS}

Legal issues surround off-label rHGH use. While the 1970 Controlled Substances Act does not list HGH as a controlled substance, ${ }^{63}$ the 1990 Anabolic Steroids Control Act criminalized the distribution of HGH as a felony punishable by up to 5 years in prison except for in the case of treatment of disease under the direction of a physician. ${ }^{1,17}$ According to the US Drug Enforcement Administration, illicit HGH distribution often stems from off-label prescribing, the black market, smuggling, or theft. Off-label or illicit prescribing frequently originates from antiaging websites or online pharmacies, where a physician prescribes HGH for a fee in lieu of an in-person examination. ${ }^{17}$ The Drug Enforcement Administration has also investigated counterfeit HGH compounds as well as oral preparations in the form of sprays or pills. ${ }^{17}$

Peer-led programs such as ATLAS (Adolescents Training and Learning to Avoid Steroids) for male athletes and ATHENA (Athletes Targeting Healthy Exercise \& Nutrition Alternatives) for female athletes have also been shown to be effective at deterring substance abuse. ${ }^{19,21}$ These educational programs can be implemented by coaches during the season, require little preparation time, and are partially facilitated by the athletes themselves. ${ }^{47,48}$

\section{CONCLUSION}

GH has been a target of potential abuse in the sporting world since at least the 1980s. While GH is approved for the treatment of adult GHD and several pediatric conditions, it is not indicated for individuals without documented deficiency. The ability of
GH to confer performance enhancement in otherwise healthy patients is uncertain at best. Furthermore, GH excess is known to have significant, multisystem adverse effects. In an effort to keep athletes safe and to ensure fair play, GH testing has been implemented by major sporting leagues, with punishments as severe as permanent disqualification levied for positive tests. The intrinsic properties of $\mathrm{GH}$ itself make accurate testing challenging. New tests with a larger testing window are being developed for use, but deterring GH abuse to begin with remains a more feasible route at present.

\section{REFERENCES}

1. 101st Congress. H.R. 4658-Anabolic Steroids Control Act of 1990. https://www .congress.gov/bill/101st-congress/house-bill/4658/text. Accessed January 18, 2018

2. Ayyar VS. History of growth hormone therapy. Indian J Endocrinol Metab 2011;15(suppl 3):S162-S165.

3. Baker JS, Graham MR, Davies B. Steroid and prescription medicine abuse in the health and fitness community: a regional study. Eur J Intern Med. 2006;17:479484 .

4. Barake M, Klibanski A, Tritos NA. Effects of recombinant human growth hormone therapy on bone mineral density in adults with growth hormone deficiency: a meta-analysis. J Clin Endocrinol Metab. 2014;99:852-860.

5. Baumann GP. Growth hormone doping in sports: a critical review of use and detection strategies. Endocr Rev. 2012;33:155-186.

6. Bollerslev J, Hallén J, Fougner KJ, et al. Low-dose GH improves exercise capacity in adults with GH deficiency: effects of a 22-month placebo-controlled, crossover trial. Eur J Endocrinol. 2005;153:379-387.

7. Brennan BP, Kanayama G, Hudson JI, Pope HG Jr. Human growth hormone abuse in male weightlifters. Am J Addict. 2011;20:9-13.

8. Burt MG, Gibney J, Hoffman DM, Umpleby AM, Ho KK. Relationship between GH-induced metabolic changes and changes in body composition: a dose and time course study in GH-deficient adults. Growth Horm IGF Res. 2008;18:55-64.

9. Buzzini SR. Abuse of growth hormone among young athletes. Pediatr Clin North Am. 2007:54:823-843.

10. Camacho-Hübner C. Normal Physiology of Growth Hormone and InsulinLike Growth Factors in Childhood. Endotext [Internet]. South Dartmouth, MA: MDText.com; 2000-2010.

11. Carroll PV, Christ ER, Bengtsson BA, et al. Growth hormone deficiency in adulthood and the effects of growth hormone replacement: a review. Growth Hormone Research Society Scientific Committee. J Clin Endocrinol Metab. 1998;83:382-395

12. Cenci MC, Soares DV, Spina LD, et al. Effects of 5 years of growth hormone (GH) replacement therapy on cardiac parameters and physical performance in adults with GH deficiency. Pituitary. 2009;12:322-329. 
13. Chinoy A, Murray PG. Diagnosis of growth hormone deficiency in the paediatric and transitional age. Best Pract Res Clin Endocrinol Metab. 2016;30:737-747.

14. Cuneo RC, Salomon F, Wiles CM, Hesp R, Sönksen PH. Growth hormone treatment in growth hormone-deficient adults. I. Effects on muscle mass and strength. J Appl Physiol (1985). 1991;70:688-694.

15. Cuneo RC, Salomon F, Wiles CM, Hesp R, Sönksen PH. Growth hormone treatment in growth hormone-deficient adults. II. Effects on exercise performance. J Appl Physiol (1985). 1991;70:695-700.

16. Cuneo RC, Salomon F, Wiles CM, Sönksen PH. Skeletal muscle performance in adults with growth hormone deficiency. Horm Res. 1990;33(suppl 4):55-60.

17. Drug Enforcement Administration. Human growth hormone. https://www .deadiversion.usdoj.gov/drug_chem_info/hgh.pdf. Accessed January 18, 2018.

18. Dubourg J, Messerer M. Sports-related chronic repetitive head trauma as a cause of pituitary dysfunction. Neurosurg Focus. 2011;31(5):E2.

19. Elliot DL, Goldberg L, Moe EL, et al. Long-term outcomes of the ATHENA (Athletes Targeting Healthy Exercise \& Nutrition Alternatives) program for female high school athletes. J Alcohol Drug Educ. 2008;52:73-92.

20. Gibney J, Wallace JD, Spinks T, et al. The effects of 10 years of recombinant human growth hormone (GH) in adult GH-deficient patients. J Clin Endocrinol Metab. 1999;84:2596-2602.

21. Goldberg L, Elliot DL, Clarke GN, et al. The Adolescents Training and Learning to Avoid Steroids (ATLAS) prevention program. Background and results of a model intervention. Arch Pediatr Adolesc Med. 1996;150:713-721.

22. Götherström G, Svensson J, Koranyi J, et al. A prospective study of 5 years of GH replacement therapy in GH-deficient adults: sustained effects on body composition, bone mass, and metabolic indices. J Clin Endocrinol Metab. 2001;86:4657-4665.

23. Growth Hormone Research Society. Consensus guidelines for the diagnosis and treatment of growth hormone $(\mathrm{GH})$ deficiency in childhood and adolescence: summary statement of the GH Research Society. J Clin Endocrinol Metab. 2000;85:3990-3993.

24. Gunawardane K, Karup Hansen T, Sandahl Christiansen J, Lunde Jorgensen JO. Normal Physiology of Growth Hormone in Adults. Endotext [Internet]. South Dartmouth, MA: MDText.com; 2000-2015.

25. Ho KK; 2007 GH Deficiency Consensus Workshop Participants. Consensus guidelines for the diagnosis and treatment of adults with GH deficiency II: a statement of the GH Research Society in association with the European Society for Pediatric Endocrinology, Lawson Wilkins Society, European Society of Endocrinology, Japan Endocrine Society, and Endocrine Society of Australia. Eur J Endocrinol. 2007; 157:695-700.

26. Holt RI. Detecting growth hormone misuse in athletes. Indian J Endocrinol Metab. 2013;17(suppl 1):S18-S22.

27. Ives JC, Alderman M, Stred SE. Hypopituitarism after multiple concussions: a retrospective case study in an adolescent male. J Athl Train. 2007;42:431-439.

28. James JS. Human growth hormone approved for wasting. AIDS Treat News. 1996;254:1-4.

29. Jørgensen JO, Thuesen L, Müller J, Ovesen P, Skakkebaek NE, Christiansen JS. Three years of growth hormone treatment in growth hormone-deficient adults: near normalization of body composition and physical performance. Eur J Endocrinol. 1994;130:224-228

30. Katznelson L, Laws ER Jr, Melmed S, et al; Endocrine Society. Acromegaly: an endocrine society clinical practice guideline. J Clin Endocrinol Metab. 2014; $99: 3933-3951$.

31. Kelestimur F, Tanriverdi F, Atmaca H, Unluhizarci K, Selcuklu A, Casanueva FF Boxing as a sport activity associated with isolated GH deficiency. J Endocrinol Invest. 2004;27:RC28-RC32.

32. Langelier DM, Kline GA, Debert CT. Neuroendocrine dysfunction in a young athlete with concussion: a case report. Clin J Sport Med. 2017;27:e78-e79.

33. Lindsay R, Feldkamp M, Harris D, Robertson J, Rallison M. Utah Growth Study: growth standards and the prevalence of growth hormone deficiency. J Pediatr. 1994;125:29-35.

34. Liu H, Bravata DM, Olkin I, et al. Systematic review: the effects of growth hormone on athletic performance. Ann Intern Med. 2008;148:747-758.

35. Major League Baseball. Major League Baseball's Joint Drug Prevention and Treatment Program. http://mlb.mlb.com/pa/pdf/jda.pdf. Accessed January 18, 2018.

36. Meazza C, Pagani S, Travaglino P, Bozzola M. Effect of growth hormone (GH) on the immune system. Pediatr Endocrinol Rev. 2004;1(suppl 3);490-495.

37. Meinhardt U, Nelson AE, Hansen JL, et al. The effects of growth hormone on body composition and physical performance in recreational athletes: a randomized trial. Ann Intern Med. 2010;152:568-577.

38. Mitchell G. Report to the Commissioner of Baseball or an independent investigation into the illegal use of steroids and other performance enhancing substances by players in Major League Baseball. http://files.mlb.com/mitchrpt.pdf. Accessed January 18, 2018.

39. Molitch ME, Clemmons DR, Malozowski S, Merriam GR, Vance ML; Endocrine Society. Evaluation and treatment of adult growth hormone deficiency: an Endocrine Society clinical practice guideline. J Clin Endocrinol Metab. 2011;96:1587-1609.

40. Nass R, Huber RM, Klauss V, Müller OA, Schopohl J, Strasburger CJ. Effect of growth hormone (hGH) replacement therapy on physical work capacity and cardiac and pulmonary function in patients with hGH deficiency acquired in adulthood. J Clin Endocrinol Metab. 1995;80:552-557.

41. National Basketball Association. NBA, NBPA to add HGH testing into anti-drug program. http://www.nba.com/2015/news/04/16/nba-and-nbpa-to-introducehgh-blood-testing/. Accessed January 18, 2018.

42. National Collegiate Athletic Association. Drug-testing exceptions procedures. http://www.ncaa.org/health-and-safety/sport-science-institute/drug-testingexceptions-procedures. Accessed January 18, 2018.

43. National Collegiate Athletic Association. Frequently asked questions about drug testing. http://www.ncaa.org/sport-science-institute/topics/frequently-askedquestions-about-drug-testing. Accessed January 18, 2018.

44. National Collegiate Athletic Association. NCAA Medical Exception Documentation Reporting Form-pre-approval for treatment with anabolic agents or peptide hormones. http://www.ncaa.org/sites/default/files/SSI AnaPepMedicalExceptionForm_20171206.pdf. Accessed January 18, 2018.

45. National Football League Players Association. Drug program resources. https:// www.nflpa.com/active-players/drug-policies. Accessed January 18, 2018.

46. National Hockey League. NHL, NHLPA team up against performance-enhancing substances. http://www.nhl.com/ice/page.htm?id=26397. Accessed January 18, 2018.

47. Oregon Health and Science University, School of Medicine, Health Promotion and Sports Medicine. ATHENA. http://www.ohsu.edu/xd/education/schools/ school-of-medicine/departments/clinical-departments/medicine/divisions/hpsm/ research/athena.cfm. Accessed January 18, 2018.

48. Oregon Health and Science University, School of Medicine, Health Promotion and Sports Medicine. ATLAS. http://www.ohsu.edu/xd/education/schools/ school-of-medicine/departments/clinical-departments/medicine/divisions/hpsm/ research/atlas.cfm. Accessed January 18, 2018.

49. Powell-Jackson J, Weller RO, Kennedy P, Preece MA, Whitcombe EM, Newsom Davis J. Creutzfeldt-Jakob disease after administration of human growth hormone. Lancet. 1985;2(8449):244-246.

50. Red C. Effectiveness of NFL's HGH policy in question. http://www.nydailynews .com/sports/football/effectiveness-nfl-hgh-policy-question-article-1.2515232. Accessed January 18, 2018.

51. Richmond EJ, Rogol AD. Growth hormone deficiency in children. Pituitary. 2008;11:115-120.

52. Rickert VI, Pawlak-Morello C, Sheppard V, Jay MS. Human growth hormone: a new substance of abuse among adolescents? Clin Pediatr (Phila). 1992;31:723726.

53. Rodríquez-Arnao J, Jabbar A, Fulcher K, Besser GM, Ross RJ. Effects of growth hormone replacement on physical performance and body composition in $\mathrm{GH}$ deficient adults. Clin Endocrinol (Oxf). 1999;51:53-60.

54. Rokkas T, Pistiolas D, Sechopoulos P, Margantinis G, Koukoulis G. Risk of colorectal neoplasm in patients with acromegaly: a meta-analysis. World J Gastroentrol. 2008;14:3484-3489.

55. Sartorio A, Narici MV. Growth hormone (GH) treatment in GH-deficient adults: effects on muscle size, strength and neural activation. Clin Physiol. 1994;14:527537.

56. Saugy M, Robinson N, Saudan C, Baume N, Avois L, Mangin P. Human growth hormone doping in sport. Br J Sports Med. 2006;40(suppl 1):i35-i39.

57. Stanley T. Diagnosis of growth hormone deficiency in childhood. Curr Opin Endocrinol Diabetes Obes. 2012;19:47-52.

58. Tanner JM, Goldstein H, Whitehouse RH. Standards for children's height at ages 2-9 years allowing for heights of parents. Arch Dis Child. 1970;45:755-762.

59. Tanriverdi F, Unluhizarci K, Coksevim B, Selcuklu A, Casanueva FF, Kelestimur F. Kickboxing sport as a new cause of traumatic brain injury-mediated hypopituitarism. Clin Endocrinol (Oxf). 2007;66:360-366.

60. Tanriverdi F, Unluhizarci K, Kelestimur F. Pituitary function in subjects with mild traumatic brain injury: a review of literature and proposal of a screening strategy. Pituitary. 2010;13:146-153.

61. Tanriverdi F, Unluhizarci K, Kocyigit I, et al. Brief communication: pituitary volume and function in competing and retired male boxers. Ann Intern Med. $2008 ; 148: 827-831$.

62. United States Anti-Doping Agency. Therapeutic use exemptions (TUEs). https:// www.usada.org/substances/tue/. Accessed January 18, 2018. 
63. United States Department of Justice, Drug Enforcement Administration. Title 21 United States Code (USC) Controlled Substances Act. https://www.deadiversion .usdoj.gov/21cfr/21usc/index.html. Accessed January 18, 2018.

64. Vilar L, Vilar CF, Lyra R, Lyra R, Naves LA. Acromegaly: clinical features at diagnosis. Pituitary. 2017;20:22-32.

65. Widdowson WM, Gibney J. The effect of growth hormone (GH) replacement on muscle strength in patients with GH-deficiency: a meta-analysis. Clin Endocrinol (Oxf). 2010;72:787-792.

66. Widdowson WM, Gibney J. The effect of growth hormone replacement on exercise capacity in patients with GH deficiency: a metaanalysis. J Clin Endocrinol Metab. 2008;93:4413-4417.

67. Wolinski K, Czarnywojtek A, Ruchala M. Risk of thyroid nodular disease and thyroid cancer in patients with acromegaly-meta-analysis and systematic review. PLoS One. 2014;9:e88787.

68. Woodhouse LJ, Asa SL, Thomas SG, Ezzat S. Measures of submaximal aerobic performance evaluate and predict functional response to growth hormone (GH) treatment in GH-deficient adults. J Clin Endocrinol Metab. 1999;84:4570-4577.

69. World Anti-Doping Agency. Guidelines. Human growth hormone (hGH) biomarkers test. https://www.wada-ama.org/sites/default/files/resources/files/ wada-guidelines-for-hgh-biomarkers-test-v1.0-2015-en.pdf. Accessed January 18, 2018.

70. World Anti-Doping Agency. Human growth hormone (HGH) testing. https:// www.wada-ama.org/en/questions-answers/human-growth-hormone-hgh-testing. Accessed January 18, 2018.

71. World Anti-Doping Agency. Medical information to support the decisions of TUE committees—growth hormone deficiency (adult). https://www.wada-ama.org/ sites/default/files/resources/files/WADA-MI-Growth-Hormone-\%28Adult\%292.0.pdf. Accessed January 18, 2018.

72. World Anti-Doping Agency. Prohibited list. https://www.wada-ama.org/sites/ default/files/resources/files/2016-09-29_-_wada_prohibited_list_2017_eng_final .pdf. Accessed January 18, 2018.

73. World Anti-Doping Agency. Therapeutic use exemptions. https://www.wadaama.org/en/what-we-do/science-medical/therapeutic-use-exemptions. Accessed January 18, 2018.

74. Xue P, Wang Y, Yang J, Li Y. Effects of growth hormone replacement therapy on bone mineral density in growth hormone deficient adults: a meta-analysis. Int J Endocrinol. 2013;2013:216107.

For reprints and permission queries, please visit SAGE's Web site at http://www.sagepub.com/journalsPermissions.nav. 